\title{
Seguindo o Trânsito: Movimentos e Caminhos, Fluxos e Águas
}

\author{
FOLLOWING THE TRANSIT: MOVEMENTS AND PATHS, FLOWS AND WATERS
}

SIGUIENDO EL TRÁNSITO: MOVIMIENTOS Y CAMINOS, CORRIENTES Y AGUAS

\author{
Juliana Dos Santos Nunes*1 \\ jujukanunes@gmail.com \\ Recibido: 31/3/2020 Aceptado: 12/8/2020
}

\begin{abstract}
Resumo
0 presente ensaio tem como objetivo apresentar a pesquisa desenvolvida na cidade de Jaguarão, fronteira do Brasil com o Uruguai, tendo como tema principal as águas, a partir dos pescadores e pescadoras, especialmente aquelas e aqueles vinculados à Colônia Z-25, situada às margens do rio. Além disso, procurou-se evidenciar a metodologia utilizada na trajetória do campo: as caminhadas etnográficas, fundamentais para alcançar o campo e também a fotografia, numa confluência entre as grafias. Também se evidenciou a cidade a partir das suas margens, tendo em vista a localidade onde se encontra situada a Colônia das pescadoras e pescadores, bem como seus locais de moradia, que em sua maioria estão situados nos bairros de periferia da cidade. Para finalizar, pensou-se numa pampa pluriversa, habitada e praticada a partir das águas, em contraste com aquela pampa do vazio ou somente ocupada pelas grandes monoculturas de arroz ou pelas criações de gado.
\end{abstract}

Palavras-chave: fluxos, caminhos, fronteiras, etnografia, águas.

\section{Resumen}

Este ensayo tiene como objetivo presentar las investigaciones desarrolladas en la ciudad de Jaguarão, frontera de Brasil con Uruguay, teniendo como tema principal las aguas, a partir de los pescadores y pescadoras, especialmente las vinculadas a la Colonia Z-25, ubicada a orillas del río. Además, se destacó la metodología utilizada en la trayectoria del campo: caminadas etnográficas, fundamentales para llegar al campo y también la fotografía, en una confluencia entre las grafías. La ciudad también se evidenció desde sus márgenes, en vista de la localidad donde se encuentra la colonia de pescadores, así como sus lugares de habitación, que en su mayoría se encuentran en las afueras de la ciudad. Por último, se pensó en una pampa pluriversa, habitada y practicada desde las aguas, en contraposición a una pampa de vacío o sólo ocupada por grandes monocultivos de arroz o por la ganadería.

Palabras clave: secuencias, caminos, fronteras, etnografía, aguas

$1 *$ Universidade Federal de Pelotas.

Tekoporá ${ }^{\circledR}$. Centro Universitario de la Región Este. Universidad de la República (C) Dos Santos (2020)

Este es un artículo de Acceso Abierto distribuido bajo licencia Creative Commons (CC BY NC 4.0) 


\begin{abstract}
This essay aims to present the research developed in the city of Jaguarão, border of Brazil with Uruguay, having as main theme the waters, from fishermen and fisherwomen, especially those linked to the Colony Z-25, located on the banks of the river. In addition, we tried to highlight the methodology used in the trajectory of the field: ethnographic walks, fundamental to reach the field and also photography, in a confluence between the spellings. The city was also highlighted from its margins, in view of the locality where the fishermen's colony is located, as well as its places of residence, which are mostly located in the outskirts of the city. Finally, a pluriverse pampa, inhabited and practiced from the waters, was thought of as opposed to that pampa of emptiness or only occupied by large rice monocultures or cattle raising.
\end{abstract}

Key words: streams, paths, borders, ethnography, waters

A presente pesquisa tem como objetivo, apresentar os caminhos, fluxos e movimentos relativos as águas, tendo como contexto a cidade de Jaguarão, fronteira do Brasil com o Uruguai e como interlocutores os pescadores e pescadoras vinculados à Colônia Z25 situada às margens do rio Jaguarão.

A cidade de Jaguarão está situada na fronteira sul do Brasil com o Uruguay, fazendo divisa com Rio Branco. A ocupação territorial se deu em meados do século XVIII em meio a intensas disputas territoriais e assinaturas de acordos e tratados para a delimitação do espaço, entre as coroas de Portugal e Espanha. Essas contendas passaram pelos limites aquáticos da fronteira, lembrando que durante o período cisplatino não havia tal delimitação, ou seja, toda essa região era "uma terra só": "a região chamada Cisplatina foi anexada ao Brasil em 1821 e Jaguarão deixou de ser uma cidade de fronteira internacional" (Demutty, 2015, p.25).

Dessa maneira ocorreram intensas trocas não somente comerciais, mas também culturais e sociais. Mais ainda, é a partir dessas águas que podemos evidenciar as profundezas de Jaguarão, uma cidade feita de movimentos, de trânsito de pessoas e coisas, pois a cidade é: "feita essencialmente de movimento. [...] este movimento é o de fazer-cidade." (Agier, p. 484).

Ainda irá se tratar sobre as caminhadas etnográficas que auxiliaram na chegada aos interlocutores e interlocutoras da pesquisa, usando-as como parte da metodologia. Buscou-se, também, mostrar a partir da fotografia, a paisagem que compõem esses fluxos e caminhos e suas intersecções: a pesca se dá entre as grandes plantações de arroz, o gado bovino e equino, entre os pássaros das mais variadas espécies, bem como os animais de estimação que acompanham alguns desses pescadores e pescadoras.

Nesse sentido, a fotografia apresentou-se como parte da grafia e do método antropológico e não apenas para ilustrar os lugares pelos quais se percorreu dentro e fora do barco, como poderão perceber nas imagens, a diversidade pode ser comprovada em sua potencialidade de vida e de relacionalidade com outras espécies, incluindo os humanos.

\title{
0 Começo - a nascente em trânsito
}

Caminhar pelos passadiços escondidos de Jaguarão é um desafio para todas e todos que por lá chegam e lançam seu olhar na tentativa de ir além do centro histórico e seu conjunto arquitetônico, hoje patrimônio nacional, no entanto para quem é da cidade, mas não vive seu cotidiano a imposição é de revisitar lugares que vão se perdendo na fumaça das lembranças, 
espaços afetivos que trazem à tona sentimentos potentes e sensíveis.

Esses trajetos, pensados a partir das narrativas e memórias dos citadinos, confundidas com as lembranças ao deslocar- se fisicamente por vielas e ruas da cidade quase desconhecida, mesmo sendo natural do local, faz reconfigurar os espaços oficiais traçados pelo plano diretor da cidade, nesse esforço para descortinar outro lugar que não mais o senso comum dos sentidos, numa narratividade do caminhar, para ir existindo no presente.

Como bem afirma as autoras Eckert y Rocha sobre essa cidade narrada, sobre as camadas temporais e as histórias que constituem esses lugares do vivido:

"Não há assim confusão entre a história da cidade e a memória restaurada na narrativa dos habitantes que tomam a cidade como objeto temporal. Narram sobre o cotidiano, sobre as formas de sociabilidade, trajetórias e estilos de interagis e de pertencer, de distinguir e de conviver na cidade que os abriga. Mas essa cidade também os narra, uma representação mais ampla que ultrapassa redes e comunidades locais. Para tanto, os habitantes narram esta experiência de acomodar em múltiplas camadas do tempo vivido as trajetórias pensadas." (Eckert y Rocha, 2010, p. 125).

Assim sendo, tudo começa pelo movimento de nossos corpos, de fazer a passo nossos trajetos e percursos, não somente no sentido de alcançarmos um ponto final das ruas (o Dédalo), vielas, becos, lugares desconhecidos, mas do processo caminhante (o Labirinto), no balanço do corpo em contato com as matérias - sensíveis, visíveis ou invisíveis - encontradas ao longo do caminho.

Uma das primeiras caminhadas que realizei para começar a pesquisa sobre o rio e as águas, se deu em outubro de 2017, após a leitura do texto 0 Dédalo e o Labirinto de Tim Ingold (2015); numa tentativa de atravessar uma cidade diferente, fiz um percurso do Cerro do Matadouro, residência de minha avó, até a beira do Rio Jaguarão (em torno de 6 quilômetros), não fazendo múltiplas escolhas (ou pelo menos tentando), mas seguindo a direção na qual o caminho se dava em linha reta, aproximando com mais lógica e sentido os pontos mencionados. Neste caso, fugindo ao Dédalo.

Ali diante daquelas águas, ao notar a cidade vizinha de Rio Branco - UY refletida no espelho calmo do rio me veio à cabeça a palavra nosotros: que segundo Schlee teria como significado nós no outro, a alteridade refletida naquilo que constitui o espaço crítico da cidade, ou seu ponto crucial, seu drama, vendo nós mesmos no lado de lá do rio e vendo os outros no lado de cá, aqui lembro o texto de John Dawsey sobre os bonecos da Rua do Porto: "a sensação de quem está se vendo sendo visto por outro. E de outro lugar." (Dawsey, 2012, p. 189).

No entanto, quando o rio se torna barro na época das secas, notamos o perigo de sua ausência, que em sonho apareceu para mim não existindo mais, revelando assim a inutilidade da ponte e sua internacionalidade, assim a mimesis se apaga, pois é o rio que faz surgir essas semelhanças ou evidencia as diferenças: "através da mimesis, ou do dom de produzir semelhanças e de tornar-se semelhança, evidenciam-se uma forma de conhecimento e um modo de relacionar-se com o mundo." (Dawsey, 2012, p. 196).

Enquanto explorava o território, conversei com dois pescadores que se encontravam parados diante de uma peixaria, observando o horizonte e a calmaria daqueles dias; eram dois homens, perguntei da associação, de como se dava a pesca, se pescavam nas redondezas ou se iam longe, percebi certa resistência, não estendi a conversa e segui flutuando com versos na cabeça.

Caminhar com vagar, sentindo a fluidez do corpo em contato com os lugares, com o ritmo 
dos passos, procurando fazer o caminho ou quem sabe sonhar com as asas de Ícaro, um voyeur (Certeau, 1998, p. 170), seguindo o rio até dar de golpe com a Ponte Internacional Mauá, com os "encantados" que por ali se escondem, com as histórias que nos contam, desde a construção, ao marco aquático que divide nossa fronteira (Demutty, 2015).

Essa prática do andarilhar, ou como referiu Peixoto y Silveira (2019), dessas "caminhadas anfíbias" (p.03) permeia todo processo de perceber uma cidade a partir das águas, ou melhor, parece-me um desvelar da cidade a partir do movimento das águas e dos seus percursos e trajetórias, Dona Rosa disse- me: "tudo começou aqui, e eu brigo muito pela valorização", nesse sentido, penso a partir da frase de Rosa, que o rio oferece uma dádiva (justamente a água não somente como recurso, como também no simbolismo, nas relações de amizade e afeto e de sustentabilidade, como pensa Marcel Mauss: dar, receber e retribuir para as cidades, não podemos esquecer que se trata de uma fronteira, pautada justamente por suas relações com as águas, são elas o primeiro ponto de contato entre aqueles que ocupam os dois lados de cada banda.

Seguindo os passos de esse transitar, desse modus transeunte, tão caro para quem vive e está entre fronteiras, e fundamental para quem tem a água como principal meio de subsistência e locomoção, Ingold (2015) nos revela o seguinte: “... as ruas não são labirinto. Nós andamos por elas não pelo que revelam ao longo do caminho, mas porque elas nos permitem transitar de um ponto ao outro." (p.24).

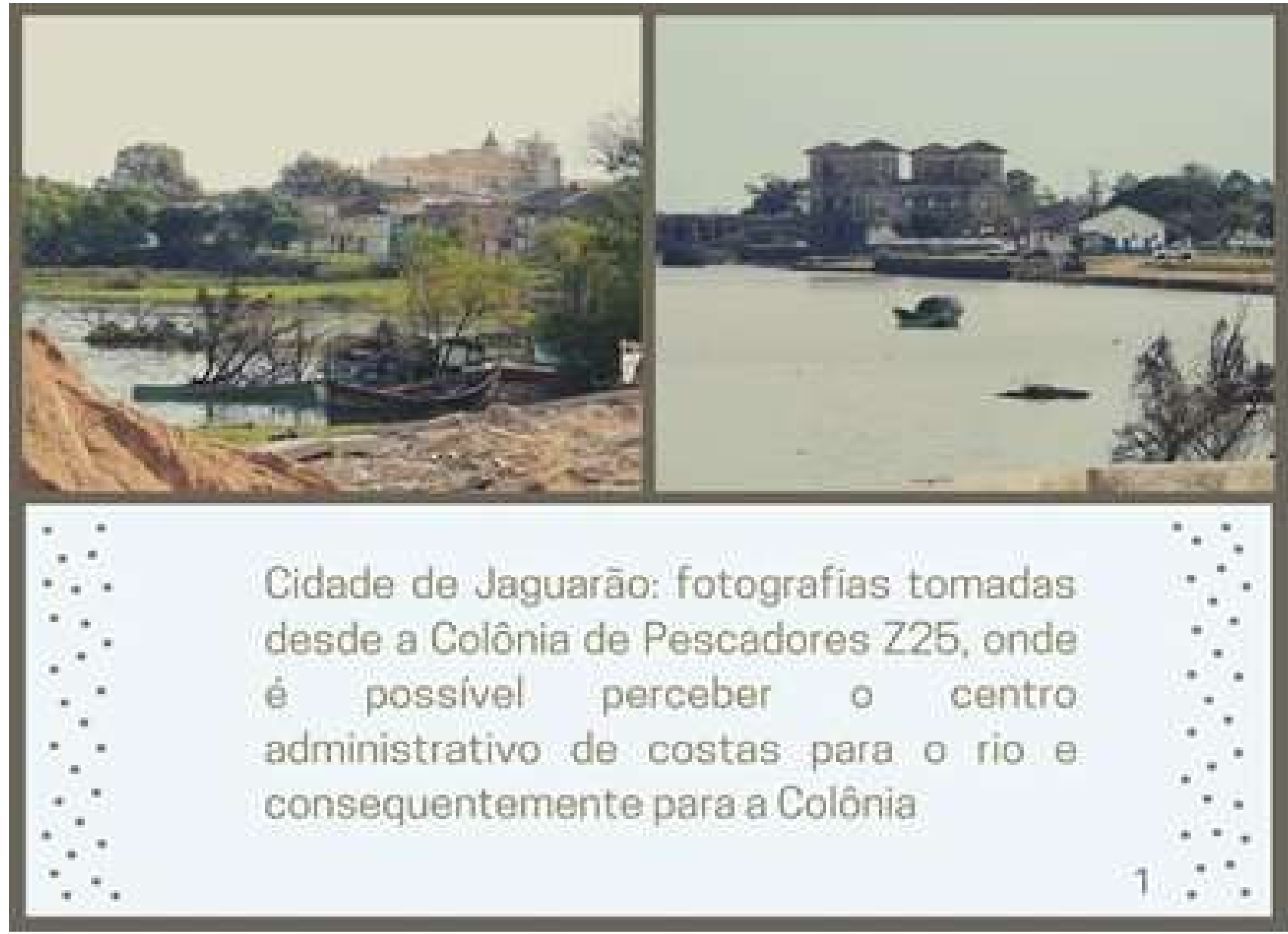

Fig. 01 - Cidade de Jaguarão, Ponte Internacional Mauá e Colônia Z-25 
Dessa maneira, pensando nos movimentos e concepções das trabalhadoras e trabalhadores das águas, pensando-as na cidade, situando a fronteira do Brasil com o Uruguay, estendendo a reflexão a fim de pensar sobre uma pampa aquática e as perspectivas plurais, desveladas a partir dos pescadores da Colônia Z25 situada às margens do Rio Jaguarão.

0 primeiro encontro que tive com Dona Rosa foi, digamos, por acaso. Havia ido à casa da pescadora Juliana, a qual conheço desde a infância, nesse dia conversamos poucos minutos, mas foram suficientes para pensar um bocado de horas. Naquele dia, ao perguntar o que significava o rio para ela, Rosa responde: "o rio é um trânsito, é só um trânsito" (Diário de Campo, outubro de 2019).

Confesso que, num primeiro momento, fiquei desapontada, me senti uma neófita sendo desafiada (o que é maravilhoso e me coloca na ex-dução apontada por Ingold) a pensar no que seria isso de ser "somente trânsito", no entanto ao relatar para as professoras sobre isso, venho novamente o que Marisol de la Cadena (2018) refere, é mais que trânsito: "essa relação - em que as pessoas e o território estão juntos - excede as possibilidades dos humanos modernos e da natureza moderna, bem como as relações modernas entre eles, sem excluí-las. (p.98).

Nesse sentido, o rio sendo um trânsito deixa evidentes os movimentos, intencionais, por conta da atividade pesqueira, ou seja, uma prática da qual todas e todas dependem para a sobrevivência, mas também se trata de movimentos atencionais, que se deixam fluir pela forma como se pratica e se habita a cidade pelas águas, como disse De la Cadena (2018), excede a concepção moderna de existir, pois se rege por um tempo ordenado em comunhão com a natureza.

Quando nos reencontramos em sua residência, na qual permaneci todo tempo numa espécie de corredor, retomei a questão do rio enquanto trânsito para tentar compreender, então surge a seguinte frase: "o rio é o nosso caminho, é tudo, é ele quem nos leva para a lagoa." (Rosa, Diário de Campo, novembro de 2019).

Caminhar segundo Ingold (2015) é: "o ato de caminhar continuamente nos remove longe de qualquer posição que possamos adotar. Caminhar, explica Masschelein, é colocar em questão essa posição; trata-se de ex-posição, de estar fora de posição." (p.28).

Seguindo o ritmo desse trânsito e do tempo, Rosa pontua aquilo que a cidade também é, ou seja, um lugar de passo, como a própria música de Jorge Drexler afirma em sua letra, "no tenemos pertenencia, sino equipaje". Dessa maneira ela narra o "fazer cidade" como pontua Agier (2015), esse lugar que se reflete e se pensa nas águas e nos seus espelhos, nas suas temporalidades, em seus encontros e desencontros:

"Quando a cidade conta de si mesma é como a cristalização do mirar-se nas águas, a palavra nasce da contemplação da cidade no rio. As palavras evocam a imagem-reflexo da cidade, que como nas águas é incerta, sempre por fazer-se na profundidade do ato narrativo onde o tempo é distendido, é o tempo de uma identidade relacional." (Peixoto y Silveira, 2019, p.08).

Portanto, são esses fluxos, entre as palavras e as águas, que montam esse cenário da fronteira, mostrando uma pluralidade de viver na pampa sul-rio-grandense, de enxergar novos ritmos para uma cidade que está de costas para o rio, conforme se pode notar pela posição do centro administrativo do município, explicitado por Rosa ao comentar sobre a sensação de invisibilidade da comunidade pesqueira. Ver foto nas pranchas.

Segundo Eckert y Rocha (2010) "é nos relatos de vida destes citadinos apreendidos em suas narrativas que procedemos a interpretação das formas de viver sociabilidades e interações nos ritmos da vida cotidiana" (p.126).

Percebe-se na narrativa das interlocutoras que a cidade guarda sua contradição ao invisibilizá-los, enquanto trabalhadores e também o rio, por ter se tornado agente passivo da 
poluição, para exaltar a profissão Rosa afirma: "levo minhas pescadoras em tudo", além de tentar auxiliar alguns areeiros a fim de que possam se organizar enquanto categoria.

Portanto, percebe-se nesses diálogos iniciais uma série de perspectivas relacionais com a água, desde os conflitos em torno de sua potabilidade e preservação, bem como as narrativas de dona Rosa e sua filha Rosângela a respeito do experienciar diariamente essa cidade aquática, evidenciando as contradições de um lugar que nasce às margens de um rio.

\section{Meandrico - pescadores, pescadoras e suas histórias}

Como refleti mais acima, a água apresenta diversas nuances, especialmente no seu trânsito, mas também perante a cidade, a invisibilidade está pronunciada pela configuração da própria cidade, além disso tem dupla personalidade, desde produtora de vida e alimento, de trazer calma e consolo para os dias mais brutais, mas também possui uma potência destruidora, capaz de arrasar aqueles que vivem na terra, destruindo suas habitações e causando afogamentos.

Essas características da água são evidenciadas pelas interlocutoras e interlocutores quando de nossos encontros, sempre se traz a questão dessas potencialidades destruidoras e benéficas. Dona Rosa mostra um fascínio pela água e não nega seus afogamentos e quase morte por causa deles. No entanto, quando as cheias se apresentam no rio Jaguarão, ela manda a água entrar em sua casa e sai sorridente para ver as águas transbordantes, conforme fotografia ao lado.

Para boa parte dos pescadores com quem tive contato, a água remete a um universo carregado de fascínio e mistérios, muito embora mostre sua potência destruidora, é preciso ter respeito com ela, conversar, conviver, conforme Seu Olimar, pescador pertencente ao Sindicato de Pescadores de Jaguarão, também advindo de uma linhagem de homens marítimos como ele mesmo denomina. Para Olimar antes de pescar "tem que conversar com os bichos primeiro, não pode chegar na água de primeira." (Diário de Campo, abril de 2019).

Santiago, genro de dona Rosa, muito devoto de Nossa Senhora Aparecida, com quem guarda fé e proteção, pensa que "a água, tu pede licença para entrar... te faço um convite, vai na beira de uma água para sentir, os problemas vão embora." (Diário de Campo, novembro de 2019).

Para Rosângela, com uma frase pontual ela diz o que pensa sobre a água: "a água rege tudo, ela sabe a hora de entrar e sabe a hora de sair." (Diário de Campo, novembro de 2019). Nesse sentido, a água como força vital, de vontade própria, de vivência e potência. Segundo Peixoto y Silveira, novamente com seu trabalho interessante sobre Salvaterra diz o seguinte:

"As trocas entre humanos e águas extrapolam a dimensão utilitária e funcional e se estende a uma relação de respeito em que, o dar, o receber e o retribuir estão imersos em simbolismo $e$ afetividade, que regulam as formas de lidar com o ambiente em termos simbólico-práticos, com forte caráter ritualístico". (Peixoto y Silveira, 2019, p.14).

Além disso, percebe-se uma relacionalidade e uma horizontalidade nas relações entre seres de gêneros distintos, nesse caso a água e os pescadores, assim chegamos ao conceito de "ontologia relacional que no distingue entre cosas naturales y culturales" (Blaser, 2015, p.05) como se pode notar a partir dos diálogos acima descritos, assim referi na proposta inicial deste texto, há uma lógica distinta de pensar o ambiente, não como meio, mas como partícipe da experiência do viver.

Segundo Escobar (2012) essas ontologias relacionais: "son aquellas en las cuales los 
mundos biofísicos, humanos y supernaturales, no se consideran como entidades separadas, sino que se establece vínculos de continuidad" (p.07). Aqui começamos a vislumbrar a pampa pluriversa, delineada por outras maneiras de praticá-la e de habitá-la (Certeau, 1998), contrastando com a historiografia oficial de que essa seria uma terra de planuras e lonjuras, de cavalos, gado e inabitada.

Seria um equívoco classificar esse lugar como universo, estaria dessa maneira descartando a diversidade da grande "reunião de vidas" como afirma Ingold, são movimentos de vidas mostrando seres em relacionalidade, construtores de lógicas distintas e de maneiras diversas de se locomover pelo mundo, pois se está tratando de lidas aquáticas, de gente que vive nas intempéries, que pesca pra fora, camperiando peixes, vivendo nos banhados até o momento de alcançar a lagoa mirim.

Assim, nos traz à tona não somente uma pluriversalidade de relações de trabalho e vivência, mas também de ocupação do próprio espaço, de uma lida campeira brabíssima, do deslocar-se por caminhos inóspitos a partir de seus barcos: "Somos do Mar, Falcão 5o, Unidos no Mar, pedindo que a água os proteja com as bênções de Nossa Senhora Aparecida.

Para adensar a compreensão da pampa pluriversa, Mário Blaser nos traz a seguinte afirmação: “... a la noción de ontologias múltiples ya que nos protege del error de confundir ontologia con un mapa mental del mundo: en este resgitro una ontologia es una manera de hacer mundo, es una formar de enactuar la realidad." (p.07).

Como uma proposta inicial, está se consolidando uma maneira diferente de se enxergar

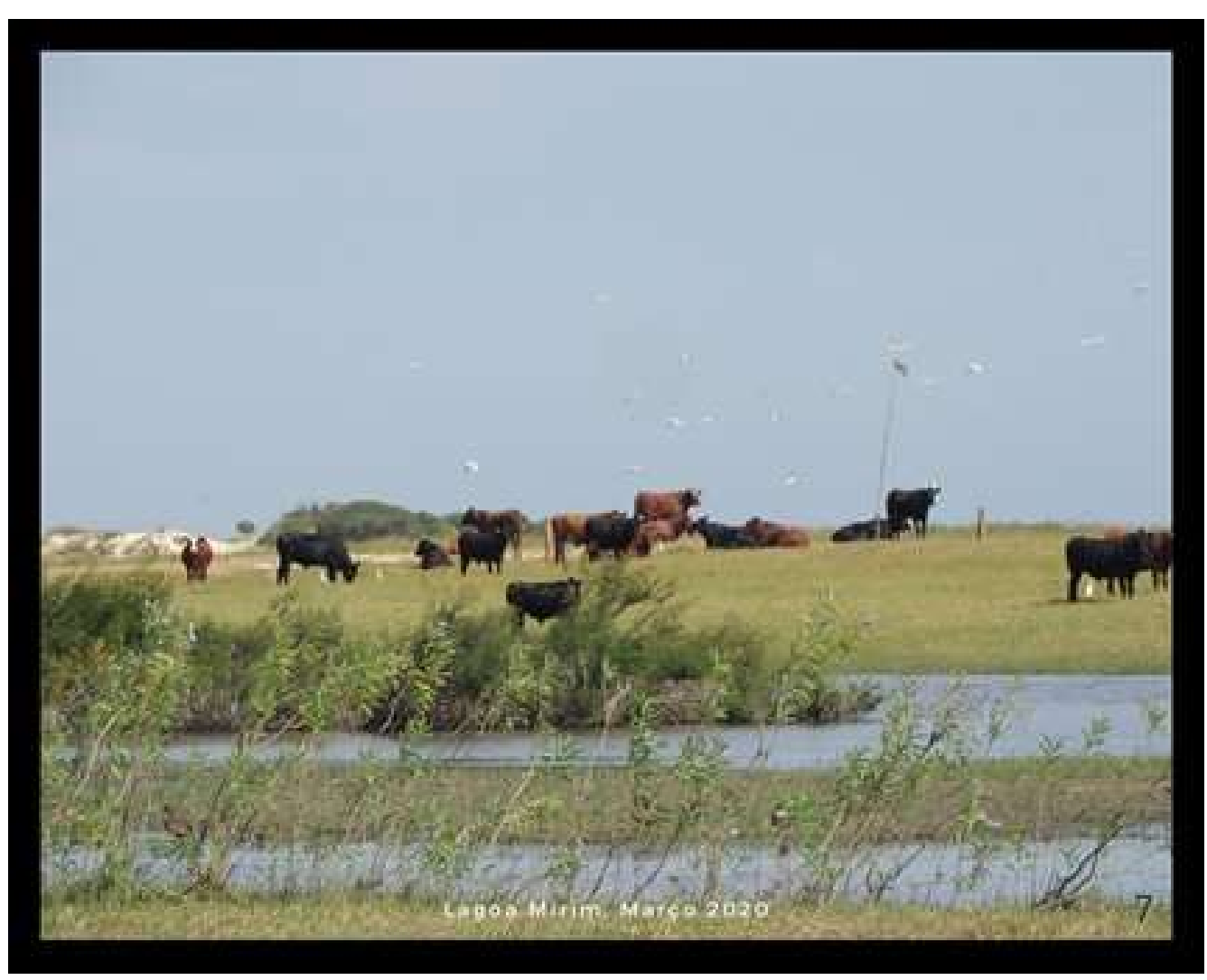

nossa região a partir da relação com

interlocutores, trazendo suas experiências de vida, seus trânsitos e movimentos, mostrando formas diversas de se viver as lonjuras desses campos, desses banhados, dessas águas, desses meandros.

\section{Conclusão}

- Pampa - água pluriversa

Fig. 02 - Lagoa Mirim, Campos Banhados, Vacas, Pássaros

Nos caminhos e fluxos diversos descritos até aqui, foi possível perceber, ainda que de maneira incipiente, por ser uma pesquisa em andamento, o contexto etnográfico pampeano às 
margens do rio, das águas que correm para a lagoa e que também servem de sustento e de demarcador político-cultural de dois países.

As águas ameaçadas pelo veneno e pela falta de saneamento básico, represadas a fim de que não seja salgada, conforme me contaram as pescadoras e pescadores da Colônia Z-25 de Jaguarão, são as mesmas que podemos observar de forma pujante em boa parte da paisagem pampera, muito embora sejam as planícies e grandes extensões de campo os destaques dessa região.

Segundo Daniel Vaz (2015), a pampa pode ser entendida como: "uma área cultural" (Leal apud Vaz, 2015, p. 196) que, por meio da mobilidade de humanos e não humanos, ultrapassa os limites geográficos e políticos do Brasil, adentrando na paisagem cultural dos países lindeiros: Uruguai e Argentina." (p.196)

Considerando a vastidão de seus campos e paisagens, 700 mil KM $^{2}$ (idem, 2015) nos admiramos com a paisagem uniforme retratada como típica da região, mas que, no entanto, traz consigo uma diversidade de viver e produzir novas formas de sustentabilidade, que nos faz questionar sobre o imaginário de uma pampa vazia e inabitada ou dos grandes campos povoados pelas grandes fazendas de monocultura de arroz.

Ao percorrer a estrada entre Pelotas a Jaguarão percebi uma metáfora para a paisagem pampeana: o banhado. Essas águas, ou espelhos, estão da na paisagem de maneira indelével e potente que me fez pensar nessa inundação, nessa vazante pampeira que gera uma lógica diferenciada, pois são nesses mesmos banhados que as pescadoras e pescadores de Jaguarão tiram seu sustento em algumas épocas do ano.

Nestes mesmos espaços aquáticos podem-se ver o gado pastando quando as águas recuam, bem como outras espécies locais: patos, marrecos, galinhas d"água, flamingos, além dos cachorros que fazem companhia aos pescadores que acampam na beira dos canais que dão acesso à Lagoa Mirim.

Entendo que essa pampa é feita em comum, escondida no meio das macegas, onde avistamos uma pluriversalidade de espécies que compõem a região. Sobretudo, são nítidos como os próprios espelhos, que os açudes, taipas, banhados, rios e seus braços são parte potente da paisagem pampera, desses rincões latino-americanos, assim como igualmente é claro, diáfano, que esses espelhos estão desaparecendo, a seca deixa evidente o espinhaço do campo, tapado pelas grandes monoculturas que dilaceram e desestruturam diversas cadeias produtoras, assim como rios e lagoas.

Os pastos queimados, o gado lutando como pode, a terra seca e daninhosa, a terra invadida desde tiempos, vê-se de longe aquelas colinas meio verdes, meio enferrujadas, as nuvens carregadas, mas carecendo chuva de todos os tipos. Os peixes sufocados por uma água tingida por aquilo que sai das plantações de arroz.

É uma localidade que verte água da terra, feito o dia em que andei de barco com o casal de pescadores, Rosângela e Santiago, sentindo o movimento das águas de maneira diversa, aquela sensação do corpo sentido o deslocar-se do barco rumo à lagoa e ouvir Rosângela me dizer: "Estás vendo ali? São os lençóis freáticos, olha a água saindo", levei um tempo para conseguir enxergar o que ela me dizia, até que vi aquela água saindo da terra, da pampa e todo resto de seres convivendo naquele mesmo lugar.

Aqui penso nas ontologias relacionais de Arturo Escobar (2016) e no sentipensar: "estos saberes están particularmente sintonizados con las necesidades de la Tierra [...] aquellos que los producen sentipiensan con la Tierra" (Escobar, 2016, p. 14).No entanto, não se pode tornar o cenário onde se as pescadoras e pescadores vivem seu cotidiano de trabalho e também de 
lazer, como algo idílico, pois se encontro essas relacionalidades ontológicas, também encontro o conflito e a violência, a disputa pelos lugares onde a fronteira é uma linha muito tênue e invisível a olho nu.

Nesse sentido, é possível perceber esse sentipensar, mas aqui caberia um sentipensar com las águas pampeiras e com o pluriverso que constitui a paisagem: há gado e peixes juntos (sensação boa de ouvir as tainhas beliscando as orelhas), há pássaros de todos los colores e hay gentes habitando essa pampa de maneiras variadas e convivendo como podem entre campos e banhados.

A pampa água y tierra (pachamama), teta (talvez assustada) e sangre desses pagos, mãe serena e resistente, de onde vem vida, alimento e a vontade de esperançar (tomo emprestado de Paulo Freire ao falar sobre esperança em seu livro Pedagogia do Oprimido, do verbo esperançar, no sentido de ação), desses matos que estão pedindo trégua desde os tempos das primeiras invasões.

Portanto, muito embora ameaçada, percebe-se que há uma configuração pluriversa nessa frontera pampeana, habitada por diferentes pessoas e constituída das suas vivências, não somente na forma de "manejar" os lugares, vivendo aqui ou allá, mas também na própria paisagem, nas vazantes e inundações, nos seus banhados e espelhos.

\section{Referências}

Agier, M. (2015). Do direito à cidade ao fazer-se cidade. 0 antropólogo, a margem e o centro. Mana 21 (3), pp. 483-498.

Blaser, M. (2015). Reflexiones sobre la Ontología Política de los Conflictos Meioambientales. Conferência Pronunciada no Seminário Internacional de Pensamento Contemporâneo, Cauca, Colombia: Universidade de Cauca.

Cadena, M. de la. (2018). Natureza incomum: histórias do antropo-cego. Revista do Instituto de Estudos Brasileiros, Brasil, (69), pp.95-117.

Certeau, M. D. (1998). A Invenção do Cotidiano: Artes de Fazer. Petrópolis, Brasil: Editora: Vozes.

Dawsey, J. C. [2011] (2012). Bonecos da Rua do Porto: performance, mimesis e memória involuntária. Ilha, Florianópolis, 13, (1), pp. 185-219. Demutty, C. N. (2015). Jaguarão, suas águas e o Tratado de 1909: uma reflexão a partir das charges da revista careta. Trabalho de Conclusão de Curso. História Licenciatura. Universidade Federal do Pampa - Jaguarão.

Escobar, A. (2012). Cultura y diferencia. Revista de Investigación en Cultura y Desarrollo.

Escobar, A. (2016). Sentipensar con la Tierra: Las Luchas Territoriales y la Dimensión Ontológica de las Epistemologías del Sur. Revista de Antropología Iberoamerica, 11(1), pp. 1132.

Eckert, C., Rocha e Carvalho A. L. da. (2010). Cidade narrada, tempo vivido: estudos de etnografia da duração. Revista Rua, Campinas, 1(16).

Ingold, T. (2015). O dédalo e o labirinto: caminhar, imaginar e educar a atenção. Horizontes 
Antropológicos 21(44), pp. 21-36.

Peixoto, L. B. L. e Silveira, F. L. A. da. (2019). Da água, a palavra: uma reflexão sobre as relações entre cidade e cursos d"água em Salvaterra a partir da memória de seus habitantes. Ponto Urbe - Revista do núcleo de antropologia urbana da USP, 24.

Vaz, D. L. (2015). "O cavalo é quem te dá as dicas": uma etnografia da relação entre domadores e cavalos no pampa brasileiro. Revista de Antropologia da UFSCAR, 7(1), jan./jun, pp. 193-210. 